\title{
The New Paradigm of Management in Design Organization: The Reality of Bottom-line Effectiveness in Design Organization's Management Needs
}

\author{
Seungpok Choi ${ }^{*}$ \\ Interior Design Dept. \\ Silla University, Busan, Korea
}

\begin{abstract}
This study identifies how management theory and philosophy work in conjunction with and support one another as both are critical to understanding leadership concepts and viewing the design organization holistically in terms of organizational behavior and performance. This paper analyses data from an in-depth single-case study at management in interior design organization in Korea. Two new 'most efficient and effective way' to achieve the goals of the design organization has been launched. The first was organizational behavior and performance, and the second a needed new paradigm of management skills. Organizational culture affects organizational effectiveness in design because it can (a) provide an organization with a competitive advantage, (b) improve the way an organizational structure works, and (c) increase the motivation of designers to pursue organizational interests. Moreover, the result of research creates paradigm of thinking that how leaders in the design organization need to focus on innovative and strategic systems to gain competitive advantage and enter global markets; a key inter-organizational cooperation strategy to achieve a targeted goal.
\end{abstract}

Keyword: design organization, philosophy and theory, innovative and strategic systems

\section{INTRODUCTION}

Organizational activities in design field is undergoing significant change is the process of ongoing improvement within organizations. Running a design organization is challenging and takes time, but with the right planning, and a little nurturing and patience, it is not as difficult as it might first appear. The role of the designer has clearly shifted from solving simple problems to solving complex problems, and from working independently in a single-discipline focus to working collaboratively with cross-functional teams [28]. Valuation of the design management, and the differences between design thinking and design management, and offers some concrete steps that can be taken toward becoming an organization that values and profits from effective design [35].

Management theory and management philosophy look at ways to improve an organization's overall health [1]. Today's management theory is the result of the interdisciplinary efforts of many people. Management theory is a set of ideas and rules designed to help supervisors/managers in design organization. This study identifies how management theory and philosophy work in conjunction with and support one another as both are critical to understanding leadership concepts and viewing the design organization holistically in terms of organizational behavior and performance. Moreover, the research creates paradigm of thinking that how leaders in the design

\footnotetext{
*Corresponding author. E-mail : sweet@silla.ac.kr

Manuscript received Aug 09, 2011 ; accepted Dec.06, 2011
}

organization need to focus on innovative and strategic systems to gain competitive advantage and enter global markets; a key inter-organizational cooperation strategy to achieve a targeted goal.

\section{CONCEPTUAL FRAMEWORK}

A review of the literature was used to create an initial conceptualization of this study. This structure allowed for a set of specific interview questions to be formulated and provided a structure for analysis and discussion of the findings.

\subsection{Management philosophy and theory}

Management theory can be used to enhance or highlight a particular management philosophy. The major difference in these two concepts is that management theories are typically tested and will be altered or changed once they are proven to be invalid. Management philosophy, on the other hand, may change based on other factors such as market changes or innovation [37].

Both management theory and philosophy work in conjunction with and support one another as both are critical to understanding leadership concepts and viewing an organization holistically in terms of organizational behavior and performance. One aspect of organizational activities that is undergoing significant change is the process of ongoing improvement within organizations. Management theory and management philosophy look at ways to improve an 
organization's overall health [1]. Management philosophy is viewed against historical creations, innovations, management techniques as we have grown from an industrial, structural nation moved into behavioral sciences, psychology and moved further into subjective, open, theory where environment and people become the focus, not the structure. Each movement brought about a new theory, espoused by various people with different perspectives, both natural and scientific, therefore; changing management philosophy [14].

Contrary to management philosophy, the concepts of management theory are to draw attention to business profit and organizational effectiveness though clearly defined management scope, process, and systems. Management theory provides the foundation to support and foster management philosophy [17]. A business philosophy is a system of thought that explain basic business problems and supplies the basis for an intelligent approach to their solution. The philosophy of management is obviously the philosophy of business [10].

\subsection{Why needs management philosophy and theory in design Organization?}

Today's management theory is the result of the interdisciplinary efforts of many people. Management theory is a set of ideas and rules designed to help supervisors/managers in design organization: (a) to know the goals of the organization; (b) to plan work required to achieve the goals of the design organization in the most efficient and effective way possible; and (c) to understand what motivates people to work when achieving the goals of the design organization [34].

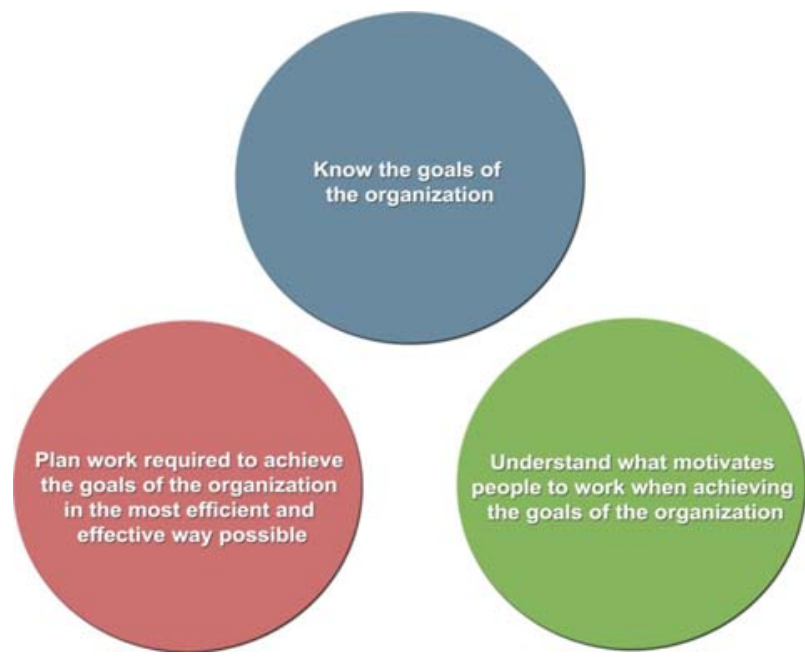

Fig. 1 Management theory

The contemporary management theory brings a more interdisciplinary approach to the design field of management. The integrative methodologies of the systems approach and contingency theory give chief designers the latitude they need to integrate the research of the many management skills [33].

\section{RESERCH METHOD}

This paper analyses data from an in-depth single-case study at management in interior design organization in Korea. Selecting a single case does not provide the confidence of a large $\mathrm{n}$ sample and inevitably raises concerns over generalizability but three factors meant that single case research was deemed particularly appropriate for this study. First, although design services are under-researched in OM there is extant theory. As a result, it was necessary to undertake both confirmatory, albeit without formal hypotheses [32], and exploratory research seeking to develop novel insight, understanding and theory enhancement [18]. Second, a key aim was to explore the nature of management philosophy within a specific organisational and institutional context. Moreover, design organization in the Korea faced a series of regulatory and competitive challenges leading nearly all firms to reconsider the nature of their management philosophy. An indepth study of a single setting was also important in allowing the researchers to become familiar with the details of the profession. Third, the specific design organization case was selected because it offered a persuasive example [31] of the challenges associated with management in design organization. Over the last 10 years significant effort had been focused on making interior design organization 'more corporate'. Substantial organic growth, with the creation of numerous additional service lines was complemented by a number of regional and national acquisitions. Computerized time recording and legal precedent management systems had been introduced and the firm had developed a range of higher volume design service offerings incorporating digital design processing and other service technologies.

\subsection{The case study}

Interior design organization is a legal design service formed more than 20 years ago with the merger of 'traditional' legal practices. For many years it had been run "rather like a club" (Chairman) with an informal structure, no clear strategic priorities and little emphasis on managerial skills or productivity. Over the last 10 years however, under the direction of a new Managing Partner and the influence of client/market pressures, interior design organization had been focused on transforming their operations and management of those operations. Two new 'most efficient and effective way' to achieve the goals of the design organization has been launched. The first was organizational behavior and performance, and the second a needed new paradigm of management skills.

\subsection{Data collection}

The empirical data were gathered at multiple points in time and over a period of more than six month. Several sources of evidence [38] were used including documentation from interviews and meetings; field notes, outputs from participant workshops, and documents from the interior design organization. Semi-structured interviews were recorded and transcribed. All grades and types of staff were interviewed, from the Chairman and Managing designers through Team Leaders, long serving salaried and equity partners, and recently appointed junior designers, and designers. 


\subsection{Data analysis}

In order to produce a contextually detailed account of the case study, the data were carefully analysed in a multi-stage process; supported by the qualitative data analysis tool, TAMS (Text Analysis Mark-up System) Analyzer (www.tamsys.sourceforge.net/) [36]. The results were presented in order to give an opportunity to comment on key observations and initial findings. In terms of generalization, the single case study alone is not enough for a generalizable theory, but can be seen as steps towards generalization and in this case testing the applicability of a framework in a specific context.

\subsection{Findings}

Taking into account the longitudinal nature of the data, we began our analysis by splitting our sample into high and low performing interior design company. First, we averaged each company's scores over the four time periods, and then we calculated the overall average for all 22 companies. Using this mean, we split the sample, which resulted in 10 highperforming companies and 12 low-performing ones. Our onetailed t-test results suggest that organizational behavior and performance was significantly different in high- and lowperforming companies in the direction we anticipated. Second, investigating a needed new paradigm of management skills for design company, we found the results of this test are presented in Table 1. This shows the result of required plan to achieve the goals of the design organization in the most efficient and effective way possible, and to understand what motivates people to work when achieving the goals of the design organization.

Table 1. Major innovative and strategic systems for design organization

\begin{tabular}{l|l|l}
\hline $\begin{array}{l}\text { Varia } \\
\text { bles }\end{array}$ & $\begin{array}{l}\text { Innovative and } \\
\text { strategic systems }\end{array}$ & Major elements \\
\hline \hline 1 & $\begin{array}{c}\text { Diversity- } \\
\text { related } \\
\text { organizational } \\
\text { boundary- } \\
\text { spanning } \\
\text { challenges }\end{array}$ & $\begin{array}{l}\cdot \text { The characteristics of } \\
\text { organization members } \\
\cdot \text { Organizational ethics } \\
\cdot \text { The property rights } \\
\text { distributed among the people } \\
\text { in the design organization } \\
\cdot \text { Organizational structure }\end{array}$ \\
\hline 2 & $\begin{array}{l}\text { Vertical integration strategies / outsourcing strategies } \\
\text { cooperation } \\
\text { structures }\end{array}$ & $\begin{array}{l}\cdot \text { Outsourcing } \\
\cdot \text { Joint activity } \\
\cdot \text { A diversity training } \\
\text { program } \\
\cdot \text { The role of the virtual } \\
\text { corporation }\end{array}$ \\
\hline
\end{tabular}

\begin{tabular}{|c|c|c|}
\hline 4 & $\begin{array}{l}\text { Inter- } \\
\text { organizational } \\
\text { cooperation } \\
\text { leadership }\end{array}$ & $\begin{array}{l}\text { · Suspicion competition arm’s } \\
\text { length } \diamond \text { trust, value added to } \\
\text { both sides } \\
\text { · Price, efficiency, own } \\
\text { profits } \diamond \text { Equity, fair dealing } \\
\text { everyone profits } \\
\cdot \text { Information and feedback } \\
\text { limited } \diamond \text { E-business links to } \\
\text { share information and } \\
\text { conduct digital transactions } \\
\cdot \text { Lawsuits to resolve conflict } \\
\diamond \text { Close coordination virtual } \\
\text { teams and people onsite. } \\
\text { · Minimal involvement and } \\
\text { up front investment } \diamond \\
\text { Involvement in partner's } \\
\text { product design and } \\
\text { production. } \\
\text { - Short term contracts } \diamond \text { Long } \\
\text { term contracts } \\
\text { · Contracts limit the } \\
\text { relationship } \diamond \text { business } \\
\text { assistance goes beyond the } \\
\text { contract }\end{array}$ \\
\hline 5 & $\begin{array}{l}\text { Employee } \\
\text { diversity }\end{array}$ & $\begin{array}{l}\cdot \text { Race } \\
\cdot \text { Ethnicity } \\
\cdot \text { Language } \\
\cdot \text { Religion } \\
\cdot \text { Culture } \\
\cdot \text { Gender } \\
\cdot \text { Level of Education } \\
\cdot \text { Age and experiences } \\
\cdot \text { Mental, Physical, or } \\
\text { Developmental Disability } \\
\cdot \text { Gender Identity and } \\
\text { Expression }\end{array}$ \\
\hline
\end{tabular}

\section{INNOVATIVE AND STRATEGIC SYSTEMS IN DESIGN ORGANIZATION}

\subsection{Diversity-related organizational boundary-spanning challenges}

Boundary spanning is defined as or referred to as action that a focal team takes on to reach out into its environment to obtain important resources and support. Organizational boundaryspanning creates a fretwork that allows design organizations to strengthening the value chain and increasing their ability to grow and survive in a competitive environment [17].

The undertaking of boundary spanning can strongly affect team performance. Teams reach beyond organizational boundaries to map trends such as technical development that are significant to the team's activities [13]. The challenges that team member facing in the company are the barriers of creating, maintaining, and improving boundaryless customer-suppliers partnership relationship. There is six substantial barriers challenge each team member; legal and regulatory tradition, 
competitive confusions, lack of trust, difficulty in letting go of control, slowness in learning new managerial skills, and barrier complexity [3].

In boundary spanning teams also build relationships while reaching out to detect internal and external demands and promote the team's work. Effective boundary spanning can also build goodwill among designers [13]. However, team members must understand that organizational boundary-spanning in forming partnerships or alliances is process that require insight, collaborating and full cooperation of value chine members.

Organizational culture develops from the interaction of (a) the characteristics of organization members, (b) organizational ethics, (c) the property rights distributed among the people in the design organization, and (d) organizational structure [17].

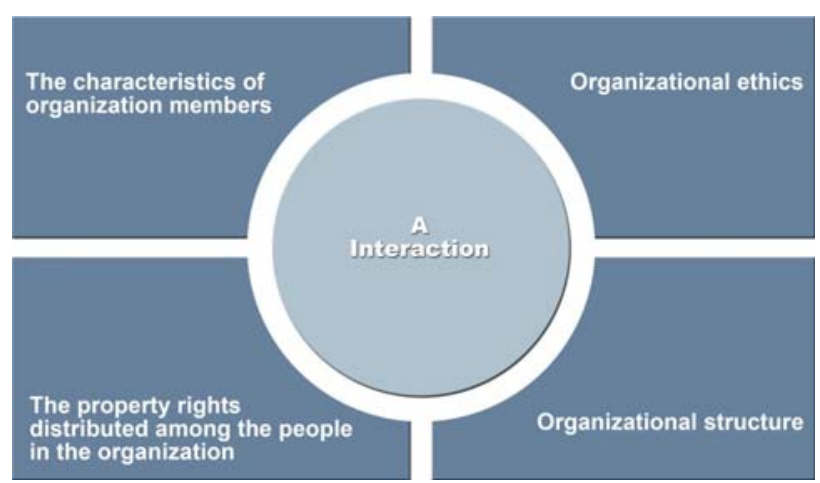

Fig. 2 Organizational culture development

Organizational culture affects organizational effectiveness because it can (a) provide the design organization with a competitive advantage, (b) improve the way an organizational structure works, and (c) increase the motivation of employees to pursue organizational interests [17].

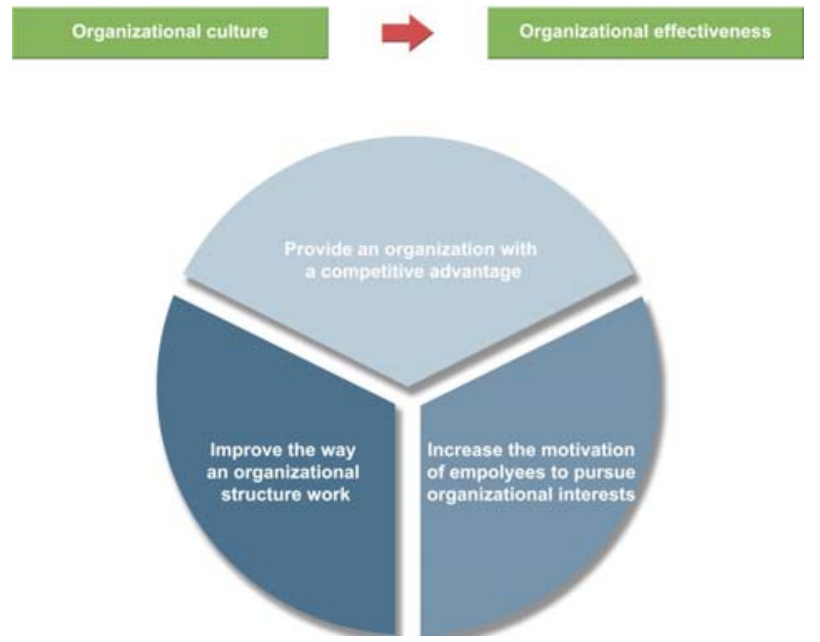

Fig. 3 Organizational effectiveness

\subsection{Vertical integration strategies / outsourcing strategies}

Outsourcing strategies creates design organizational structure that leads management to move company internal value creation activities to outside suppliers or distributers [17]. The vertical integration and outsourcing strategies decision- making processes are based on same calculation of "makes or buys" for the same organizational goals achievement from different management philosophies approaches. We need to start a project for a new product, we can immediately put together a team that can discuss things in a design-to-cost context and know what they are talking about. We think we have to keep innovation and production physically closes together [19]. Implementing a successful outsourcing strategy requires a framework. The logic of this framework can be applied to a range of business processes, including manufacturing, logistics and design. Effective outsourcing involves analyzing a number of key dimensions, including relative capability in the process, contribution of the process to competitive advantage and the potential for opportunism from outsourcing the process [21].

It's about trust and information sharing with each other so both parties can deal with unforeseen risks and uncertainties more effectively. Companies with the best outsourcing strategies use both forms of governance well since various situations call for different responses [21].

Vertical integration also allows the design organization to better control the creation of the desired culture within the organization because all processes are seamless.

Furthermore, design corporations considering vertical integration must make decisions regarding the autonomy of business unit [15].

\subsection{Intra-organizational structure}

The natural, open structure of today places additional focus on people, environment rather than structure, processes, and functions. Many companies are adjusting their style from rational, functional, or traditional to open natural companies; this is through change processes. Change is the process by which companies redesign their structure and culture to move from present state to desired state to achieve some type of effectiveness [17].

The increase in technology and the processing of communication along with the global economy mean that organizations need to be flexible, innovative, faster, and able to integrate new strategies and initiatives quickly. These new success factors conflict with the philosophy of scientific management because scientific and administrative management alone do not allow design organizations to compete effectively in today's economy. There must be a combination of both philosophies in order for design organizations to survive and to meet customer's needs [3]. A boundary-less organization is one in which there are no barriers to information flow. Instead of boundaries separating people, jobs, processes, and places, ideas, information, decisions, and actions move to where they are most needed [4].

\subsection{Inter-organizational cooperation structures}

Organizational outsourcing structure is tied closely to coordinate inter-organizational cooperation. Outsourcing structure enables an increase of organizational competitive advantages, avoids internal bureaucratic costs, reduces 
operating, manufacture processes, new project develop, and finished goods costs through vendor and supplier management and coordinating activities [5].

\subsubsection{Outsourcing}

Sometimes outsourcing is accompanied with a negative connotation. Outsourcing is allowing another company to perform services or build products that otherwise could have performed internally. This process involves restructuring activities in order to stimulate the development by externalizing less important activities [8]. In addition, Bustinza \& GutierrezGutierrez defines four basic types of outsourcing:

(1) General outsourcing, which covers three alternatives: (a) selective outsourcing, (b) value-added outsourcing or (c) cooperative outsourcing.

(2) Transitional outsourcing, which involves the process of moving from one technological platform to another.

(3) Business process outsourcing: a relationship in which a third party supplier performs an entire business function for the client organization.

(4) Business benefit contracting: This refers to a "contractual agreement that defines the vendor's contribution to the client in terms of specific benefits to the business and defines the payment the customer will make based upon the vendor's ability to deliver those benefits" [8].

\subsubsection{Advantages of outsourcing}

The main purpose for outsourcing is that it is a cost saving strategy for the company.

1. Take advantage of the cost-advantages!

2. See an increase in your business

3. Save Big!

4. Get access to specialized services

5. Concentrate more on your core business

6. Make faster deliveries to customers

7. Improved customer satisfaction

8. Benefit from time zone advantages

9. Increased efficiency

10. Give your business a competitive edge!

11. Outsourcing countries also benefit from outsourcing [2].

\subsubsection{Disadvantages of outsourcing}

1. Loss of Managerial Control

2. Hidden Costs

3. Threat to Security and Confidentiality

4. Quality Problems

5. Tied to the Financial Well-Being of Another Company

6. Bad Publicity and Ill-Will [7].

One way of coordinating inter-organizational cooperation is by nurturing trust. Trust is a crucial element in creating and maintaining good inter-organizational relationships [12].

\subsubsection{Joint activity}

Joint activity is another way of coordinating interorganizational cooperation. This means more than just the division of labor and tasks within a cooperative environment but more of a degree to which focal activities are carried out jointly, such as long range planning, development and product design, quality and delivery coordination, training, technical assistance, and education [6]. When design organizations are confronted by rapidly changing business environment such as the products quality, the exchange rate variation, business laws and politics, logistics cost, labor shortage, culture difference in different organizations or countries, the inter-organizations coordinating relationship becomes more complicated and difficult [5].

\subsubsection{A diversity training program}

A diversity training program with mobile capacity is an effective structural form for current boundary-less organizations [16]. Advantages of this structural form are inclusion of specialized, talented workforce dispersing talent into the design organization.

The global workforce of today focuses on "putting diversity programs allow for improved leadership, new ideas, innovations, and increased specialization. The goals of a true diversity training program in the workplace should be determined by the culture and needs of the workplace in question [22].

An effective diversity program focuses on diversity issues with clients, contractors, government, and suppliers as well. A well designed diversity program assists your company in working together more effectively, and better serves the diverse customer base. Advantages of deploying this program are diminishing stereotypes, which lead to discrimination [22].

\subsubsection{The role of the virtual corporation}

A business relationship must be established among the companies along a supply chain to optimize the coordination of activities. Within virtual design organizations, independent companies are linked together to share skills, costs, and access to one another's markets and data. Therefore, a virtual design corporation may change the composition of its partners periodically or dissolve entirely once a goal has been achieved. Information technology plays a central role in the development, functioning, and success of virtual corporations. It enables teams from participating companies to work concurrently by using computer networks in real time, which, in turn, allows companies to reduce the time needed to make a product [27]. Advancements in telecommunication and computer technology such as local area network services, electronic mail, electronic data interchange (EDI), video conferencing, network of computer-aided design (CAD), and computer-aided manufacturing (CAM) systems make virtual corporations popular in every field of business.

\subsection{Inter-organizational cooperation leadership}

Inter-organizational cooperation provides design firms more opportunities to take advantage of flexibility for innovation performance by facilitating the access and dispersion of knowledge with the firms [20]. Inter-organizational cooperation is an increasingly important leadership focus because it influences the design organizational innovation in supply 
chain's effectiveness and knowledge management [3]. Leaders need to focus on innovative and strategic systems to gain competitive advantage and enter global markets; a key interorganizational cooperation strategy to achieve this goal is to focus on the supply chain management system [30]. The system helps us to understand better the nature of leadership in inter-organizational settings and as such seeks to influence the performance of leaders and ultimately the consequences of the systems they manage [9].

Managers have shifted from an adversarial orientation to a partnership orientation summarized in exhibit below "the Shift to a Partnership paradigm” [24]. From adversarial orientation $\diamond$ to partnership orientation:

1) Suspicion competition arm's length $\diamond$ trust, value added to both sides

2) Price, efficiency, own profits $\diamond$ Equity, fair dealing everyone profits

3) Information and feedback limited $\diamond$ E-business links to share information and conduct digital transactions

4) Lawsuits to resolve conflict $\diamond$ Close coordination virtual teams and people onsite.

5) Minimal involvement and upfront investment $\diamond$ Involvement in partner's product design and production.

6) Short term contracts $\diamond$ Long term contracts

7) Contracts limit the relationship $\diamond$ business assistance goes beyond the contract [24].

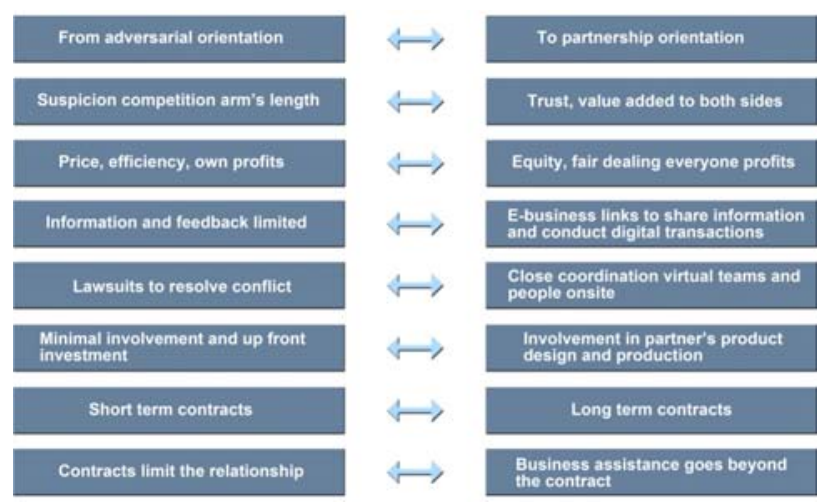

Fig. 4 The shift to a partnership paradigm

\subsection{Employee diversity}

Effective diversity depends on the effective relationships between organizational theory, structure, culture, design, and change [17]. The number of minorities is increasing in the workforce and leaders and organizations that lack the skills to embrace and leverage diversity will be at a significant disadvantage. Diversity today refers to other elements besides skin color and gender, it is now broadened to include other elements such as religious affiliation, age, disability status, military experience, sexual orientation, economic class, educational level, function or position within an organization, work style, and expectation and values [4].

The followings are element of employee diversity in the 21st century.

Race

Ethnicity
Language

Religion

Culture

Gender

Level of Education

Age and experiences

Mental, Physical, or Developmental Disability

Gender Identity and Expression

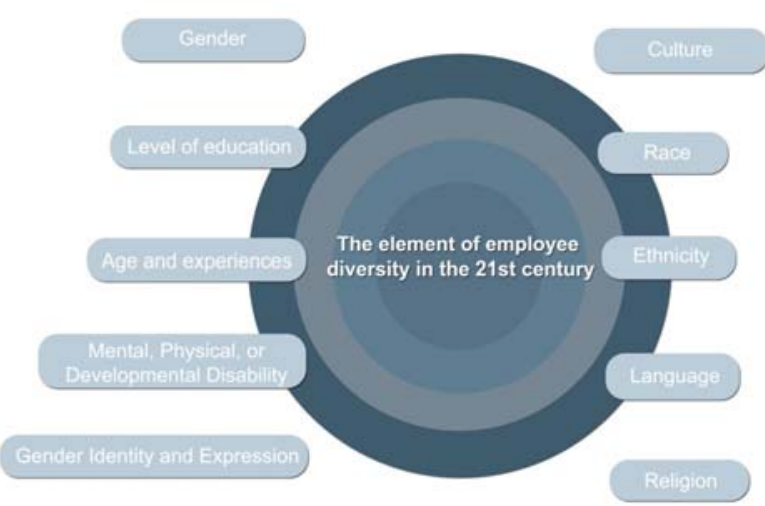

Fig. 5 Employee diversity

The design organization's plans for becoming multicultural and making the most of its diverse workforce should include (a) securing top management leadership and commitment, (b) organizational assessment, (c) attracting employees, (d) training employees in diversity, and (e) retaining employees [14]. According to Businesses that support diversity link it to the design company's strategic vision. These businesses monitor recruitment, promotion, and development trends, and reinforce the value of diversity in hiring. They are committed to technical re-education, and pay attention to subtle reinforcements of a homogenous ideal [26].

Knowledge management (KM) deals with the transfer of information and the recording of information in such a way that it can be used in the future for the benefit of the company. KM can impact three different professional settings: coaching and training, designing, and service settings. It has reiterated the impact of KM on one level might lead to synergistic impacts on another. Thus, KM has the potential to produce several interconnected impacts on people, design products, processes, and organizations [29].

Communication has and continues to be a challenge in design organizations. Communication is one of the primary dimensions of the design organization, and significantly influences effectiveness of any tem or enterprise. In my organization the diversity that I identify is ethnicity, reluctance to accept other cultures. In 2020, if the mindsets of individuals have not changed ethnicity diversity will be a challenge [25]. Developing culture of the company that promises each individual a similar feeling of appreciation, inclusion and acknowledge of their talents constitutes a necessary element of managing diversity [25].

The most challenging element that design organization faces in terms of leveraging diversity is an aging workforce. Stereotypes that exist for older generations are: they are slow learners, resistant to change, have an increase in illnesses, and 
unwilling to adapt. However, we believe by losing an aging workforce, we lose invaluable experience and I would hope that in the future the design organization would incorporate strategies to leverage this element such as, phased out retirement plans and adapting the work environment to assist with poorer vision, hearing, and mobility [4]. This element of diversity will also be a challenge for the design organization in the future. In addition to an aging workforce another element that will be challenging for the design organization is work style, expectation and values. As our workforce ages, more of our tenured and experienced employees are strongly encouraged to retire. The rapid changes in technology and the requirements for leaders are demanding. And while the organization continues to position itself to compete effectively, it is demanding more time from its employees. Although the organization says it values work-life balance, at times that line is thin and barely visible.

\section{CONCLUSION}

Both management theory and philosophy work in conjunction with and support one another as both are critical to understanding leadership concepts and viewing the design organization holistically in terms of organizational behavior and performance. Research suggests that the undertaking of boundary spanning can strongly affect team performance in design organization. Teams reach beyond organizational boundaries to map trends such as technical development that are significant to the team's activities. The challenges that team member facing in the company are the barriers of creating, maintaining, and improving boundary-less customer-designers partnership relationship. Organizational culture affects organizational effectiveness in design because it can (a) provide an organization with a competitive advantage, (b) improve the way an organizational structure works, and (c) increase the motivation of designers to pursue organizational interests (Jones, 2010, p. 202). Moreover, design corporations considering vertical integration must make decisions regarding the autonomy of business unit. Implementing a successful outsourcing strategy requires a framework. The logic of this framework can be applied to a range of business and design processes, including manufacturing, logistics and other design. Therefore, Leaders in the design organization need to focus on innovative and strategic systems to gain competitive advantage and enter global markets; a key inter-organizational cooperation strategy to achieve this goal is to focus on the supply chain management system.

- Management theory and philosophy work in design organization

- Diversity-related organizational boundary-spanning challenges

- Organizational culture affects organizational effectiveness

- The autonomy of business and design unit in vertical integration

- Contribution of the process to competitive advantage and the potential for opportunism from outsourcing the process

- Leaders need to focus on innovative and strategic systems

\section{REFERENCES}

[1] Adams, A. J., Gupta, M., \& Raho, L. (2007). Perceptions of Management Philosophies. Journal for Quality \& Participation, 30(2), 34. Retrieved from EBSCOhost.

[2] Advantages of outsourcing. (n.d.). Outsource2India. Retrieved March 24, 2011 doi:http://www.outsource2india.com/why_outsource/artic les/benefit_outsourcing.asp

[3] Ashkenas, R., Ulrich, D., Jick, T., \& Kerr, S. (2002). The boundryless organization: Breaking the chains of organizational structure. (2nd ed.). San Francisco, CA: Jossey-Bass.

[4] Bateman, T. S., \& Snell, S. A. (2007). Management: Leading \& collaborating in competitive world. New York, NY: McGraw-Hill/Irwin.

[5] Beamish, P. W., Morrison, A., Inkpen, A., \& Rosenzeig, P. M. (2003). International management: Text and cases (5th ed.). Boston, MA: McGraw-Hill/Irwin.

[6] Bensaou, M. M. (1997). Interorganizational Cooperation: The Role of Information Technology an Empirical Comparison of U.S. and Japanese Supplier Relations. Information Systems Research, 8(2), 107. Retrieved from EBSCOhost.

[7] Bucki, j. (n.d.). Outsourcing disadvantages: Reasons that outsourcing is bad for your company. About.com. Retrieved March 4, 2011 from http://operationstech.about.com/od/outsourcing/tp/O utSrcDisadv.htm

[8] Bustinza, L., \& Gutierrez-Gutierrez, L.. (2010). Outstanding as seen from the perspective of knowledge management. Journal of Supply Chain Management, 46(3), 23-39. Retrieved March2 4, 2011, from ABI/INFORM Global. (Document ID: 2243579861).

[9] Connelly, D. (2007). Leadership in the Collaborative Interorganizational Domain.

[10] Davis, R. C. (1951). The Fundamentals of Top Management. New York: Harper and Brothers.

[11] Debasis, B. (2008). Leadership styles and information security in small business: results of an empirical investigation. Debasis, D.B.A., University of phoenix.

[12] Dorit, T., \& Miri, L. (2008). Interorganizational cooperation: the structural aspect of nurturing trust. The International Journal of Public Sector Management, 21(7), 704-722. Retrieved March 3, 2011, from ABI/INFORM Complete. (Document ID: 1582860301).

[13] Faraj, S., \& Yan, A. (2009). Boundary work in knowledge teams. Journal of Applied Psychology, 94(3), p. 604-617.

[14] Gupta, A., \& Hammond, R. (2005). Information systems security issues and decisions for small businesses: An empirical examination. Information Management \& Computer Security, 13(4), 297.

[15] Harrigan, K. (1985). Vertical integration and corporate strategy. Academy of Management journal, 28(2). p. 397425 
[16] Harvey, C. (2009). Understanding and Managing Diversity. Pearson Educating Inc. Retrieved on March 2, 2011 from www.ecampus.phoenix.edu.

[17] Jones, G. (2010). Organizational theory, design, and change. (6th ed.). Upper Saddle River, NJ: Prentice Hall.

[18] Karwan, K.R. \& Markland, R.E. (2006). Integrating service design principles and information technology to improve delivery and productivity in public sector operations: the case of the South Carolina DMV. Journal of Operations Management, 24 (4), p. 347-362

[19] Lawrence, K. (2005). Vertical integration, not outsourcing. Machine Design. p. 84

[20] Martine-Sanchez, A., Vela-Jimenez, M., Perez-Perez, M., \& Carnicer P. D. (2009). Inter-organizational cooperation and environmental change; Moderation effects between flexibility and innovation performance. British Journal of Management, 20, p. 537-561. doi: 10.1111/j.14678551.2008.00605.x

[21] McIvor, R. (2011). Outsourcing done right. Industrial Engineer, 43(1), p. 30-35.

[22] Mc Lauglin, J., Clemons, L., (2004)., Diversity training. Public Management, 86(5), p. 32- 35.

[23] Peterson, R.A., Kozmetsky, G, \& Ridgway, N.M. (1983). Perceived causes of small business failure: A research note. American Journal of Small Business, 8, p. 15-19.

[24] Rama, R. (2010). Inter organizational Partnerships. Retrieved Mar. 42011 from http://www.citeman.com/12494-inter-organizationalpartnerships/

[25] Rawluszko, M. (2009). Communication in the conditions of diversity. Kobieta i Biznes,(1-4), 53-56. Retrieved March 10, 2011, from GenderWatch (GW). (Document ID: 1948593941).

[26] Reuven, L. (1996). Computer integrated manufacturing: A complex information system. Production planning and control, 7(2), p. 39- 44.

[27] Ricardo, E., Dornier, P., Fender, M., \& Kouvelis, P. (1998). Global operations and logistics. John Wiley and Sons.

[28] Seungpok, C. (2010). Leadership in Design Management by Prentice Hall's Self-Assessment. International Journal of Contents, 6(2), p. 21- 27

[29] Seungpok, C. (2010). Effective shared process and application of knowledge management (KM) in interior design service industry. International Journal of Contents, 6(3), p. 65- 70

[30] Sila, I. (2007). Adoption of internet-based interorganizational systems in supply chain management and their impact on performance. The Business Review, Cambridge 9.1, 9(1), 211-217.

[31] Siggelkow, N. (2007). Persuasion with case studies. Academy of Management Journal, 50 (1). p. 20-24.

[32] Smith, A.D., Plowman, D.A., Duchon, D. \& Quinn, A.M. (2009). A qualitative study of high-reputation plant managers: political skill and successful outcomes. Journal of Operations Management, 27, p. 428-443.

[33] Stephen, W. (2004). Management Theory. New York Institute of Technology. Retrieved March. 22, 2011 from
http://docs.google.com/viewer?a=v\&q=cache:kPnTvLvaa eYJ

[34] Stoner, Yetton, Craig \& Johnston. (1994). Management. Sydney: Prentice - Hall Inc.

[35] Thomas, L. (2009). How to become a more designminded organization. DMI Review Article, 20(3). Retrieved January 8, 2010, from http://www.dmi.org/dmi/html/publications/journal/fullabs tract_d.jsp?itemID=09203LOC28

[36] Weinstein, M. (2006). TAMS analyzer: anthropology as cultural critique in a digital age. Social Science Computer Review, 24(1), p. 68-77.

[37] What is management? (1999). Retrieved March 22, 2010 from http://www.sunrisepage.com/manage/defmana.htm

[38] Yin, R.K. (2008). Case Study Research: Design and Methods, (fourth ed.), Sage Publications, California

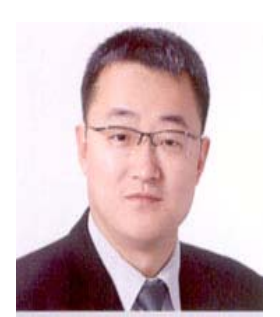

\section{Seungpok Choi}

He received the B.F.A., M.S in interior design from Pratt Institute, New York, US in 1995, 1998 respectively and is also continually studying Ph.D. in Management from university of Phoenix, US. Since then, he has been a professor of interior design department at Silla University in Korea. His main research interests include designing theme park and the aging facility, and design management. 